\title{
Estratégias de Comunicação Familiar: A Perspectiva dos Filhos Adolescentes
}

\author{
Adriana Wagner ${ }^{1}$ \\ Caroline Carpenedo \\ Lúcia Petrucci de Melo \\ Paula Grazziotin Silveira \\ Pontifícia Universidade Católica do Rio Grande do Sul
}

\begin{abstract}
Resumo
Bons níveis de saúde familiar se encontram associados a uma comunicação efetiva entre os membros da familia. A partir desta perspectiva, este estudo buscou conhecer as estratégias de comunicação utilizadas pelos adolescentes com seus pais. Participaram voluntariamente 35 estudantes com idades entre 12 e 15 anos que estavam cursando $7^{2}$ e $8^{2}$ séries do ensino fundamental. Os participantes foram divididos em 5 grupos e investigados através da técnica do grupo focal realizando-se 2 encontros com cada grupo, os quais foram gravados e, posteriormente, transcritos. Sobre o material, fez-se uma análise de conteúdo da qual emergiram 3 eixos temáticos, desmembrados em 14 categorias de conteúdos afins. Os adolescentes mostraram que possuem estratégias claras para comunicarem-se com seus pais. Dentre outras, revelaram que escolhem o momento para comunicar assuntos mais difíceis como episódios de fracasso escolar. O humor dos pais também é levado em consideração por eles na escolha do momento certo para falar.

Palavras-chave: Adolescência; estratégias de comunicação; família.
\end{abstract}

\section{Family Communication Strategies: An Adolescent Perspective}

\begin{abstract}
Good levels of family health are associated with an effective communication among family members. Using this perspective, this article aims to evaluate the adolescent strategies to communicate with their parents. 35 elementary school students, between the ages of 12 and 15 years old, participated as volunteers in this study. The students were divided into 5 groups and investigated through the focal group technique. Two meetings were performed with each group, the meetings were taped and transcribed afterwards. The content analysis resulted in 3 thematic lines, divided into 14 clear categories teenagers use to communicate with their parents. Among other things, the students revealed to choose the most appropriate moment to talk about difficult issues, such as school failure. The parents humor is also considered when choosing the right moment.

Keywords: Adolescent; communication strategies; family.
\end{abstract}

A adolescência constitui uma etapa decisiva no processo de desprendimento da família. Nesse movimento de conquista de independização e autonomia, o jovem volta-se para o meio social e apoia-se no seu grupo de iguais. Nesta fase, a familia já não é mais o centro de suas atenções. É comum, nesse processo, que o jovem apresente maior rebeldia em relação à autoridade em geral. Nessa etapa da vida, as regras costumam ser questionadas e até mesmo contestadas por ele, o que é necessário para o desenvolvimento da sua identidade (Wagner, Falcke, Silveira \& Mossmann, 2002).

É inevitável que todo o sistema familiar seja atravessado por esse processo desenvolvimental do filho adolescente, fazendo ajustes necessários para integrar essas mudanças (Maldonado,1997). Nesse sentido, a principal tarefa da familia nesse momento evolutivo é aumentar a flexibilidade das fronteiras familiares a fim de integrar os movimentos de independência dos filhos (Carter \& McGoldrick, 2001).

Esse é um processo que demanda profundas transformações, principalmente no que se refere à comunicação que se estabelece na familia. O contexto passa a ser extremamente importante para que ocorra uma conversa exitosa entre pais e filhos. Estudos indicam que a auto-estima, o bem-estar e os tipos de estratégias empregadas pelos adolescentes são variáveis que estão diretamente relacionadas com uma comunicação familiar eficaz (Jackson, Bijstra, Oostra \& Bosma, 1998). Observa-se, entretanto, nesse período que começa a existir

\footnotetext{
${ }^{1}$ Endereço para correspondência: Pontifícia Universidade Católica do Rio Grande do Sul, Faculdade de Psicologia, Av. Ipiranga, 6681, prédio 11, s. 931, 90619 900, Porto Alegre, RS. Fone: (51) 33203633 (Ramal: 224); Fax: (51) 33203633.E-mail:wagner@pucrs.br
}

um cuidado dos filhos em filtrar as informações antes de contar aos pais (Hartos \& Power, 2000), como parte do processo de autonomia e de preservação do seu espaço pessoal.

A partir das diferentes estratégias de comunicação, do conteúdo expresso nas conversas entre pais e filhos e da dinâmica de funcionamento familiar, Ríos-González (1994) caracterizou três diferentes formas de comunicação: a comunicação aberta, a superficial e a fechada. Nas familias onde os membros podem manifestar seus sentimentos e questionamentos sem sentirem-se ameaçados, provavelmente existe uma comunicação aberta, profunda, responsável e afetiva. Nesse sentido, quanto menor for o nível de desacordo entre pais e adolescentes, melhor se dará o desenvolvimento das relações familiares (Jakson \& cols., 1998; Ríos-González, 1994).

Nas famillias com fronteiras rígidas, a dificuldade de comunicação entre pais e filhos costuma ser mais freqüente, pois os jovens acabam por não confiar em seus pais que se mostram incapazes de perceber as mudanças de seus filhos adolescentes. Esses pais buscam constantemente provas da responsabilidade do filho, mas não conseguem dialogar abertamente e orientá-los quanto às dúvidas que surgem nesta fase do desenvolvimento (Cerveny \& Berthoud, 1997).

A comunicação fechada caracteriza-se por excesso de autoridade, ordens e ameaças por parte dos pais. Assim, não há espaço para os filhos manifestarem seus sentimentos e dúvidas. Dessa maneira, podese pensar que nas famillias onde a comunicação é superficial ou fechada, os membros se relacionam superficialmente e conversam apenas sobre assuntos que fazem parte do cotidiano da família, num caráter convencional (Ríos-González, 1994). 
Entre as variáveis otimizadoras e obstaculizadoras da comunicação familiar, encontra-se as diferenças de gênero. Pesquisas apontam que ambos os pais sentem maior dificuldade na comunicação com os filhos do que com as filhas (Bhushan, 1993).

Os adolescentes, por sua vez, quando comparam o relacionamento com seus pais, afirmam ser comumente mais próximos de sua mãe, revelando mais suas vivências íntimas para ela, além de falarem sobre uma variedade de assuntos mais que com o pai (Wagner \& cols., 2002). Sendo assim, os adolescentes relatam preferir suas mães para conselhos e orientação e acreditam que elas são mais abertas e iniciam mais as conversas, aceitando as opiniões dos filhos (Bhushan, 1993; Carmona, 2000; Hartos \& Power, 2000).

Considerando o aspecto pragmático da comunicação, sabese que ela afeta e é afetada pelo comportamento. Desde esta perspectiva, bons níveis de comunicação familiar são descritos como elemento de diminuição dos problemas comportamentais típicos do adolescente.

Dessa maneira, esse estudo objetiva conhecer as estratégias de comunicação utilizadas pelos adolescentes com seus pais. Essa compreensão pode auxiliar no entendimento das relações familiares, assim como na otimização dos níveis de proximidade entre pais e filhos.

\section{Método}

\section{Participantes}

Participaram deste estudo 35 adolescentes, dentre eles 24 do sexo feminino e 11 do sexo masculino, com idades que variaram de 12 a 15 anos. Estes estudantes estavam cursando a $7^{2}$ e a $8^{2}$ séries do ensino fundamental de uma escola particular de Porto Alegre.

\section{Instrumentos e Procedimentos}

Após apresentar a proposta de trabalho à direção da instituição, foi concedido aos pesquisadores o espaço para a realização do trabalho. Assim, convidamos os adolescentes para participar de uma discussão em grupos sobre o tema "Comunicação Familiar". O convite foi aberto, já que se tratava de uma atividade extra-classe. Desta forma, os interessados inscreveram-se voluntariamente para a atividade.

A técnica utilizada foi a de grupos focais, que procura conhecer e compreender as opiniões dos participantes a respeito de um determinado tema, através da interação que se estabelece entre eles (Berger, 1995; Guareschi, 1996; Morgan, 1988).

Formamos 5 grupos de adolescentes, distribuídos a partir dos seguintes critérios: alunos de diferentes turmas, idades aproximadas, com no mínimo 4 e no máximo 8 participantes de ambos os sexos. Realizaram-se ao todo 2 encontros com cada grupo, com periodicidade semanal e duração de $1 \mathrm{~h}$ cada.

\section{Resultados e Discussão}

A proposta inicial era a de discutir os aspectos facilitadores e dificultadores que os jovens encontravam para se comunicarem em casa. Solicitou-se que eles relatassem situações que consideravam haver tido êxito em comunicar as suas idéias e situações de fracasso nessa tentativa (Wagner, 2001).
Essa discussão derivou um debate sobre as estratégias que eles lançavam mão no intuito de facilitar a comunicação em casa. $\mathrm{O}$ conteúdo discutido pelo grupo foi gravado e, posteriormente, transcrito, sobre o qual realizou-se uma análise de conteúdo, buscando integrar as categorias previamente descritas na literatura sobre o tema e as informações trazidas no grupo (Olabuenaga, 1996). Assim, surgiram três eixos temáticos principais, desmembrados em categorias e subcategorias, conforme o gráfico abaixo (Para maiores detalhes, ver esquema ilustrativo das categorias no Anexo A).

Eixo Temático I: Escolha do momento oportuno reuniu respostas que referem ser muito relevante escolher o melhor momento para conversar com os pais, conforme descrito nas seguintes categorias:

O Estado de humor dos pais: esta categoria reúne respostas dos adolescentes que referem esperar o melhor estado de humor dos pais para falarem sobre determinados assuntos, pois eles acreditam que quanto mais dispostos os pais estiverem, eles tomarão decisões mais favoráveis para com eles, conforme ilustra as seguintes falas:

A gente vê como é que eles tão antes de falar alguma coisa. Vê se eles tão mal humorados, ou se eles tão felizes. (sexo fem., 15a)

Se tiver de bom humor vou falar, mas se tiver de mal humor todo mundo, eu prefiro ficar quieto. (sexo masc.,14a)

$\mathrm{Na}$ visão dos jovens, se os pais estão de bom humor, eles poderão compreendê-los melhor e, provavelmente, serão mais atenciosos. Por outro lado, na visão dos participantes o mau humor dos genitores atrapalha o bom diálogo e dificulta a relação entre pais e filhos.

O Tempo disponivel para a conversa: esta categoria evidencia a preocupação dos filhos em escolher o momento do dia para conversar com seus pais, quando eles estejam mais livres e disponíveis, conforme ilustra a fala a seguir:

Acho que assim, primeiro pra se comunicar, conversar com os pais, primeiro tem que compreender a hora deles, sei lá, tem horas que não tem como falar. (sexo fem.,13a)

Os adolescentes procuram ter sensibilidade para perceber o momento certo para falar, evitando falar algum assunto sério quando seus pais estão ocupados com seus afazeres e não podem escutá-los. Algumas vezes, porém, é interessante para os adolescentes que os pais tenham pouco tempo, principalmente, quando o assunto a ser falado é desagradável, como no caso de uma nota baixa na escola. Dessa maneira, na visão dos jovens, sobra pouco tempo para uma represália imediata, segundo as verbalizações abaixo:

Quandoé uma prova eu mostro de manhã, porque aí eles não tão cansados. Eu mostro pro meu pai quando ele está saindo para o trabalho daí não dá tempo dele brigar comigo. (referindo-se aos resultados das provas escolares) (sexo masc.,12a)

Eixo temático II: O segundo eixo descreve estratégias que dizem respeito à forma como os filhos se dirigem aos pais e a maneira 
como falam sobre determinados assuntos. Estas surgem em decorrência de conflitos esperados que levam o adolescente a estabelecer novas estratégias para negociar com seus pais (Noller \& Callan, 1991). Dentre as encontradas neste estudo destacam-se:

O jeito de falar que descreve a idéia dos adolescentes sobre as duas possibilidades de contar aos pais determinados assuntos. Alguns dizem preferir falar aos poucos e com cuidado. Desta forma, eles vão contando devagar, com o intuito de ir preparando os pais para a notícia ruim, por outro lado, alguns acreditam que falar abruptamente é a melhor forma, conforme as seguintes falas:

Eu vou devagar mostrando daí assim eu vou falando um pouco sobre a coisa assim, aí eu vou vendo o que ela (mãe) fala se ela não gosta assim, daí eu deixo pra outra hora. (referindo-se aos resultados das provas escolares) (sexo fem.,15a)

Eu vou direto ao ponto não fico fazendo rodeio. Solto a bomba e saio correndo.(referindo-se aos resultados das provas escolares) (sexo masc.,13a)

Percebe-se que para se falar algo difícil ou desagradável, os jovens, possuem estratégias claras de comunicação, ao passo que quando o assunto é agradável, ele pode ser falado a qualquer momento.

A categoria Fazer chantagem surge a partir da constatação de que a chantagem é usada com o objetivo de reverter uma decisão já tomada pelos pais. Nesse sentido, o choro foi bastante descrito como forma de fazer chantagem:

Aí eu começo a chorar, porque aí ele deixa eu ir. (referindo-se às festas) (sexo masc.,14a)

O adolescente recorre a essa estratégia procurando sensibilizar emocionalmente seus pais para conseguir aquilo que quer. Em alguns casos, há uma tentativa de despertar sentimentos de pena ou culpa nos pais por terem frustrado o desejo de seus filhos.

$\mathrm{Na}$ categoria Selecionar informações, a mentira e a omissão aparecem como estratégias de comunicação utilizadas pelos adolescentes quando eles não querem que seus pais saibam sobre determinado assunto, conforme as seguintes verbalizações:

Não, eu acho o seguinte, eu acho que não tem que falar nem pra mãe nem pro pai, pra nenhum dos dois, é complicado, eu vou lá falar com o meu pai e o meu pai não me entende, aí minha mãe não, um entende e o outro não, aí um vai tentar falar, explicar, depois já começa a falar, falar, falar. Isso enche. Eu acho que quando não tem que falar para um, não tem que falar pro outro. (sexo masc., 14a)

Normalmente, os pais de adolescentes surpreendem-se quando descobrem que seus filhos não lhes contam tudo o que acontece em suas vidas (Zagury,1996). Entretanto, é esperado que o adolescente tenha a sua intimidade preservada, uma vez que isso faz parte de seu processo de independização, conforme também postula Hartos e Power (2000).

Tratando-se da mentira, percebe-se que elas expressam o desejo do jovem em conquistar autonomia em relação aos seus pais, ou mesmo conseguir aquilo que eles desejam burlando as normas, uma vez que, se falarem a verdade parece que não serão bem sucedidos. A descoberta dessa mentira é, freqüentemente, muito decepcionante para os pais que sentem-se inseguros com isso.

Quando o meu pai diz não, eu digo pra minha mãe que ele disse sim, senão ela não vai deixar. Se ele descobre que eu menti, aí sim vem toda uma lição de moral (sexo fem.,12a)

A categoria Comparação com os outros se refere aos conteúdos em que o adolescente se compara com jovens da mesma idade e na mesma situação. O objetivo dessa estratégia é convencer os pais a tomarem uma decisão favorável ao filho, ou amenizar o impacto causado por notícias desagradáveis, conforme as seguintes falas:

A gente diz assim: ' às $5 \mathrm{~h}$ a gente tá aqui', $\mathrm{O}$ pai contesta: 'às $5 \mathrm{~h}$ não, é demais...', A filha: 'mas pai, porque não?! Todo mundo vai ficar até às $5 \mathrm{~h}$, por que eu tenho que ser a única a não ficar?'. (sexo fem.,13a)

Quando eu tiro uma nota baixa, ai eu digo 'ah, mais a nota mais alta foi, por exemplo, 7', aí eu digo, a minha mãe sabe que tem uma guria que só tira nota alta, aí eu digo 'ah, até a fulana tirou nota baixa. (sexo fem.,14a)

A categoria insistir mostra uma forma utilizada pelos adolescentes para persuadir seus pais a dar permissão para aquilo que é desejado. Nesse sentido, o objetivo principal dessa forma de comunicação é convencer a outra pessoa a mudar de idéia por meio da argumentação lógica, o que segundo Maldonado (1997) é muito freqüente na fase da adolescência.

Aí eu enchi tanto. o saco (sexo fem., 15a)

Entretanto, nem sempre a insistência é uma estratégia bemsucedida para os adolescentes, afinal em algumas famílias as regras são muito pouco flexíveis. A seguinte fala refere uma situação de fracasso da utilização da insistência como estratégia de comunicação:

Se os dois dizem sim tudo bem, mas se um diz que não, não adianta insistir pro outro, tentar convencer o outro... que é não mesmo. (sexo masc.,12a)

Sabe-se que as familias com filhos adolescentes devem ter como característica a flexibilidade, principalmente no que se refere às suas fronteiras. Sendo assim, torna-se necessário que a autoridade parental seja atenuada em certa medida, possibilitando maior independência e desenvolvimento para o adolescente (Carter \& McGoldrick, 2001).

Fazer trocas é uma categoria que descreve a maneira como os filhos procuram satisfazer suas vontades propondo aos pais trocas de favores. Essa estratégia expressa uma tentativa de negociação entre pais e filhos:

Se eu quero ir para algum lugar, daí eu me mato estudando. No ano passado um tio meu foi pra outro estado, São Paulo, se não me engano. Eu queria ir também na viagem e daí eu me matei estudando, valeu a pena depois, eu fui pro Pará, Paraná, eu acho. (sexo fem., 14a)

Pode-se pensar que esse tipo de barganha reflete uma evolução do adolescente no sentido de aquisição de responsabilidades frente ao mundo adulto. Ele percebe que já não está mais numa 
posição infantil em que recebe tudo o que deseja sem ter que arcar com as conseqüências. Nesse momento, o jovem passa a sentir a necessidade de responder aos favores concedidos por seus pais por alguma coisa em troca.

A contrapartida da comunicação é o Enfrentamento. Neste caso a estratégia enfrentar reflete a forma encontrada pelo jovem para impor a sua opinião e decisão sobre a de seus pais. Evidencia-se, então, as primeiras manifestações de que o adolescente começa a construir opinião própria, não aceitando mais tudo aquilo que os pais dizem. Essa estratégia não deve comprometer a autoridade parental, mas, propiciar um espaço de diálogo entre os membros da familia (Wagner \& cols., 2002). Em alguns casos, a expressão de uma idéia contrária pode adquirir o caráter de enfrentamento, uma vez que o jovem, freqüentemente, não consegue moderar seus argumentos, conforme a verbalização abaixo:

... eu lembro que já aconteceu várias coisas tipo, a minha mãe e meu pai falam alguma coisa e eu não concordar e tentar enfrentar ... (sexo fem., 15a)

No segundo eixo, as categorias fazer chantagem, insistir e enfrentar expressam uma tentativa de convencimento dos pais, por parte dos adolescentes. A diferença entre elas é que a chantagem tem como objetivo atingir emocionalmente os pais, enquanto que a categoria insistir se refere ao uso da argumentação lógica. O enfrentamento, por sua vez, é usado quando o jovem deseja impor uma opinião contrária a de seus pais.

O último eixo diz respeito à escolha de um familiar para conversar. Esta categoria mostra que os jovens escolhem uma pessoa determinada da familia para quem eles irão contar as suas coisas. Algumas vezes, esta escolha se dá devido a uma maior identificação com o membro da familia.

$\mathrm{Na}$ categoria pai e mãe o adolescente irá selecionar assuntos em que vai se dirigir mais à mãe e outros que escolhe para compartilhar com o pai.

Se eu quero alguma coisa eu peço pro meu pai, se eu quero ir em algum lugar eu peço pra minha mãe. (sexo fem., 14a)

Se eu quero ir numa festa eu peço pro meu pai, se eu quero ir ao shopping quero uma dica pra comprar alguma coisa eu peço pra minha mãe. (sexo fem.,13a)

Percebe-se certa influência dos tradicionais papéis atribuídos aos pais na educação dos filhos, sendo que o pai é, freqüentemente, o provedor, responsável pelo sustento financeiro, cabendo à mãe o cuidado dos filhos, sendo ela quem normalmente aconselha e acompanha emocionalmente as crianças.

Dessa maneira, os jovens afirmam escolher o pai quando necessitam de dinheiro para comprar alguma coisa, deixando para falar com a mãe quando querem permissão para sair ou quando necessitam de algum conselho.

A categoria Pai mostra uma preferência maior do adolescente em se comunicar com seu pai, independentemente do assunto a ser falado.

No caso do pai ele entende porque ele já passou pela mesma coisa que eu tô passando a minha mãe não, é diferente. (sexo masc.,14a)
No exemplo acima, aparece claramente a preferência do adolescente pelo genitor do mesmo sexo que o seu para se comunicar, indicando que ele se sente mais entendido pelo pai pelo fato dele ser homem também, corroborando os achados de Wagner (2002) e Caromona (2000).

A categoria Mãe sugere que o adolescente prefere sua mãe para comunicar os mais diversos assuntos.

... eu vou falar com a minha mãe e é diferente falar com a mãe de falar com o pai. É muito diferente. Falar de qualquer coisa, por mais que tu não tenha a pessoa da tua mãe, é com ela que tu vai ter que falar. No colégio assim, sempre pedem pra falar com a mãe. (sexo fem.,11a)

Os irmãos também foram descritos como pessoas importantes de mediação entre o jovem e os pais, por isso alguns adolescentes preferem contar seus assuntos primeiro para os irmãos para só depois contá-los aos pais, conforme as seguintes falas:

Eu falo pra minha irmã daí depois que ela fala o que ela acha daí eu já tô preparado pra mostrar pra minha mãe. (referindo-se aos resultados das provas escolares) (sexo masc., 13a)

... muitas coisas eu vou lá pedir opinião a de 19 (irmã), falar alguma coisa assim, mais até ela assim, daí as vezes a opinião dela as vezes ela pode influenciar antes de falar com a minha mãe, as vezes não influencia em nada... (sexo fem.,11a)

Essa categoria evidencia que o jovem utiliza-se do subsistema fraternal como uma estratégia de comunicação com seus pais. Sendo assim, pode-se pensar que essas alianças no subsistema fraternal podem ser um fator facilitador na comunicação familiar.

A preferência pela figura dos tios na hora de contar alguma coisa é expressada no exemplo a seguir:

O meu caso é que nem o dela, eu converso mais é com as minhas tias também. (sexo fem.,14a)

Em alguns casos, a comunicação ultrapassa as fronteiras da familia de origem, sendo que o jovem recorre aos membros da familia extensa para dialogar. Essa situação evidencia claramente o desejo do adolescente de se afastar dos pais para poder se identificar com outras pessoas, interessando-se pelo mundo externo. Na fase da adolescência, o jovem precisa romper com os antigos ídolos (pai e mãe) para crescer e se independizar (Zagury, 1996).

\section{Considerações Finais}

Os adolescentes aqui investigados revelaram possuir estratégias claras de comunicação com seus pais, principalmente, quando necessitam de alguma aprovação ou consentimento deles. Entre as estratégias utilizadas, revelaram que escolhiam o momento oportuno para comunicar assuntos mais difíceis como um episódio de fracasso escolar, por exemplo. $\mathrm{O}$ humor dos pais também é levado em consideração por eles na escolha do momento certo para falar.

Esse estudo revela, ainda, que os adolescentes percebem que existem formas diferentes para comunicar determinado assunto, sendo que algumas são mais eficazes que outras, conforme o contexto. 
O jeito de falar é definido por eles como sendo importante, na hora de dialogar com os pais. Nesse sentido, alguns preferem falar aos poucos, com cuidado, enquanto que outros preferem falar abruptamente. O que predomina na comunicação entre pais e filhos, é uma certa sensibilidade por parte do jovem em adequar a forma de comunicar-se a fim de lograr maior êxito em se expressar em casa.

Algumas estratégias utilizadas pelos adolescentes desse estudo revelam comportamentos típicos da fase desenvolvimental em que eles se encontram, como no caso da chantagem, da insistência, da mentira e da omissão. Esses dados corroboram os achados de Hartos e Power (2000) sobre o cuidado que os filhos têm nessa idade em filtrar as informações antes de contar aos pais. A escolha dessas estratégias evidenciam uma luta constante pela autonomia desejada por eles. Outros trabalhos realizados por Wagner e colaboradores (2002) também evidenciaram a importância da comunicação como expressão desse processo de construção da identidade do jovem no seio de sua familia. Nesse sentido, pode-se pensar que o sistema familiar mobiliza-se nesse período pela necessidade de adaptação frente a essa nova fase, em que os filhos já não são mais crianças. Evidencia-se aí a necessidade apontada por Carter e McGoldrick (2001) de que haja uma flexibilização das fronteiras familiares nessa fase evolutiva, a fim de que a família seja capaz de integrar os movimentos de independência dos seus filhos.

A necessidade de se fazer trocas com os pais revela que o adolescente está evoluindo para uma posição adulta, tentando, gradativamente, conquistar sua liberdade. O sistema familiar, então, deve possibilitar e permitir essas modificações, sendo que a autoridade parental deve ser atenuada, porém jamais extinta. Nesse caso, o entendimento das transformações que ocorrem na relação de pais e filhos nesta fase do desenvolvimento são importantes na definição de um bom relacionamento familiar. Quando os pais permitem que seus filhos tenham espaço para a sua individualização e a tomada de atitudes, eles estão facilitando o estabelecimento de uma boa comunicação e auxiliando estes adolescentes a tornarem-se adultos autônomos. Nessa direção, Ríos-González (1994) e Jakson e colaboradores (1998) postulam que, quanto menor o nível de desacordo entre pais e filhos adolescentes, melhores serão os níveis de desenvolvimento das relações familiares.

Outra estratégia bastante utilizada é a escolha do genitor para conversar. Nesse caso, parece que a escolha se baseia no tipo de demanda que eles têm dos progenitores. Quer dizer, alguns participantes revelaram que, dependendo do assunto, preferem falar com o pai, normalmente, quando necessitam pedir dinheiro. Assim como nas pesquisas de Wagner e colaboradores (2002) e Bhushan (1993), os resultados revelaram que as mães são mais solicitadas pelo jovem quando ele deseja pedir algum conselho. Porém, em alguns casos, o jovem mostra preferência por um dos pais para comunicar os assuntos que deseja. Nesses sentido, o que normalmente ocorre é a escolha do genitor do mesmo sexo, já que o adolescente parece acreditar que, dessa maneira, será melhor compreendido.

Os resultados desse estudo apontam que, geralmente, os irmãos e os tios atuam como mediadores na comunicação dos participantes com seus pais. A partir desta constatação, pode-se pensar que a comunicação sofre transformações na família nessa fase evolutiva, pois, como o jovem passa a requisitar, também, os elementos da familia extensa, há uma tendência à ampliação da rede familiar.

Todos os jovens que participaram do estudo demonstraram motivação e voluntariaram-se para refletir sobre o tema proposto. Provavelmente, por esse motivo pode-se pensar que esses adolescentes atribuem importância para as estratégias de comunicação que utilizam a fim de facilitar o relacionamento entre os membros e preservar a boa convivência familiar.

\section{Referências}

Berger, A. A. (1995). Media research tecbniques. Newbury Park: Sage.

Bhushan, R. (1993). A study of family communication: Parents and their adolescent children. Journal of Personality and Clinical Studies, 9, 79-85.

Carmona, J. (2000). Linha cruzada: A comunicação entre pais e filhos sobre sexualidade. Dissertação de Mestrado não-publicada, Programa de Pós-graduação, Faculdade de Psicologia, Pontifícia Universidade Católica do Rio Grande do Sul. Porto Alegre, RS.

Carter, B. \& McGoldrick, M. (2001). As mudancas no ciclo de vida familiar: Uma estrutura para a terapia familiar ( $2^{\mathrm{a}}$ ed.). Porto Alegre: Artes Médicas.

Cerveny, C. M. O. \& Berthoud, C. M. E. (1997). Familia e ciclo vital: Nossa realidade em pesquisa. São Paulo: Casa do Psicólogo.

Guareschi, P. (1996). A técnica dos grupos focais como pesquisa qualitativa. Porto Alegre: PUCRS. (manuscrito não-publicado)

Hartos, J. \& Power, T. (2000). Relations among single mother's awareness of their adolescent's stressors, maternal, monitoring, mother-adolescent communication, and adolescent adjustment. Journal of Adolescent Research, 15, 546-563.

Jackson, S., Bijstra, J., Oostra, L. \& Bosma, H. (1998). Adolescent’s perception of communication with parents relative to specific aspects of relationships with parents and personal development. Jornal of Adolescence, 21, 305-322.

Maldonado, M. (1997). A comunicação entre pais e filhos (22ª ed.). São Paulo: Saraiva. Morgan, D. L. (1988). Focus groups as qualitative research. Newbury Park: Sage.

Nichols, M. \& Schwartz, R. (1998). Terapia familiar: Conceitos e métodos ( $3^{\mathrm{a}}$ ed.). Porto Alegre: Artes Médicas.

Noller, P. \& Callan, V. (1991). The adolescent in the family. Australia: Florence.

Olabuenaga, J. (1996). Metodología de la investigación cualitativa. Bilbao: Universidad de Deusto.

Ríos González, J. A. (1994). Manual de orientación y terapia familiar. Madrid: Fundación Instituto de Ciencias del Hombre.

Wagner, A., Falcke, D., Silveira, L. \& Mossmann, C. (2002). A comunicação em famílias com filhos adolescentes. Psicologia em Estudo, 7, 75-80.

Zagury, T. (1996). O adolescente por ele mesmo ( $\left.5^{\mathrm{a}} \mathrm{ed}\right)$. Rio de Janeiro: Record.

Recebido: 20/02/2004

$1^{a}$ Revisão:06/04/2004

Aceite Final: 27/05/2004

Sobre as autoras

Adriana Wagner é Professora Adjunta da Faculdade e do Programa de Pós-Graduação em Psicologia da Pontifícia Universidade Católica do Rio Grande do Sul. Caroline Carpenedo é Graduanda em psicologia pela Pontifícia Universidade Católica do Rio Grande do Sul. É Bolsista de iniciação científica pelo CNPq. Lúcia Petrucci de Melo é Graduanda em psicologia pela Pontifícia Universidade Católica do Rio Grande do Sul. Auxiliar de pesquisa.

Paula Grazziotin Silveira é Mestre em Psicologia pela Pontifícia Universidade Católica do Rio Grande do Sul. 


\section{Anexo A}

\section{Esquema Ilustrativo das Categorias}
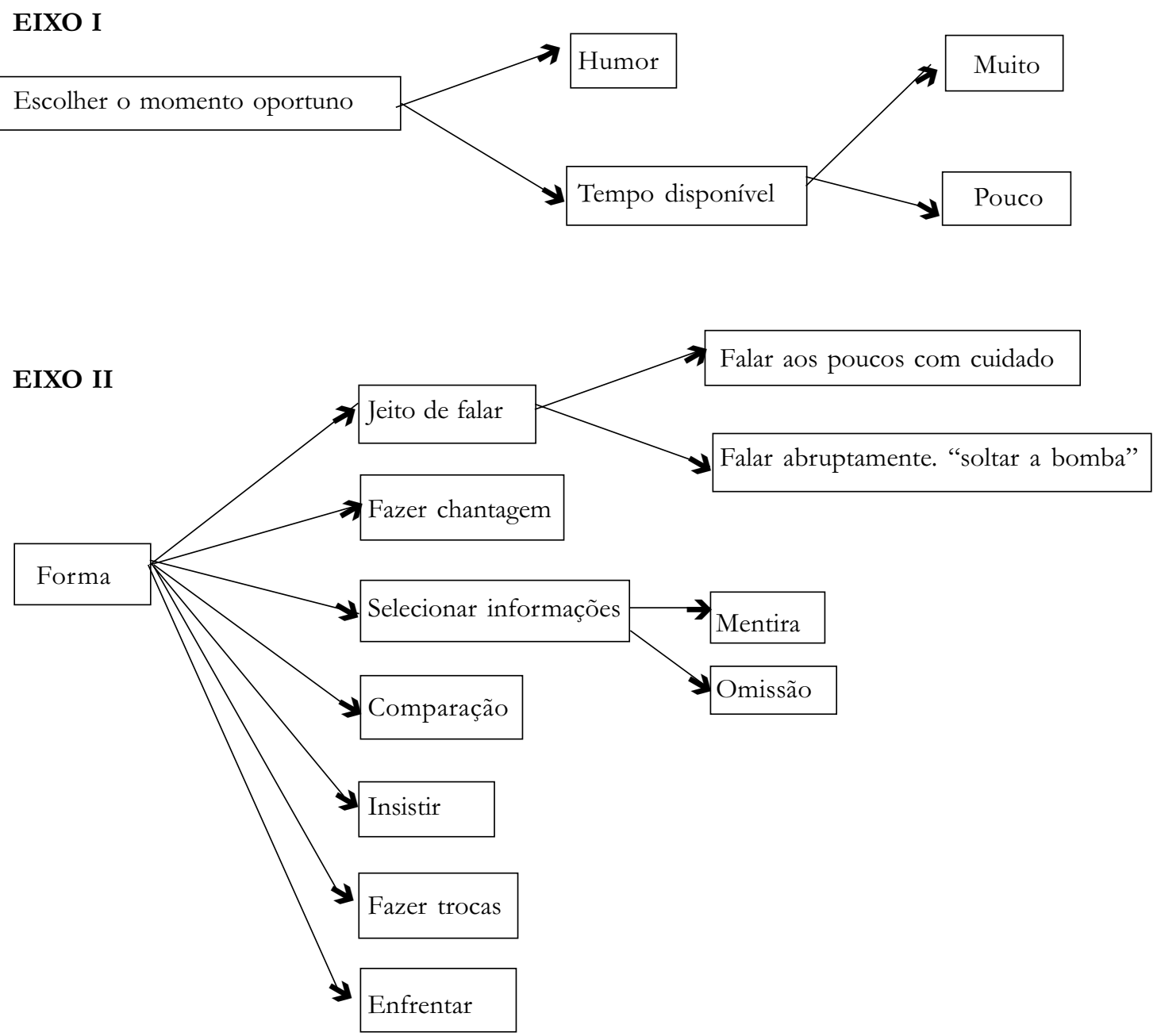

\section{EIXO III}

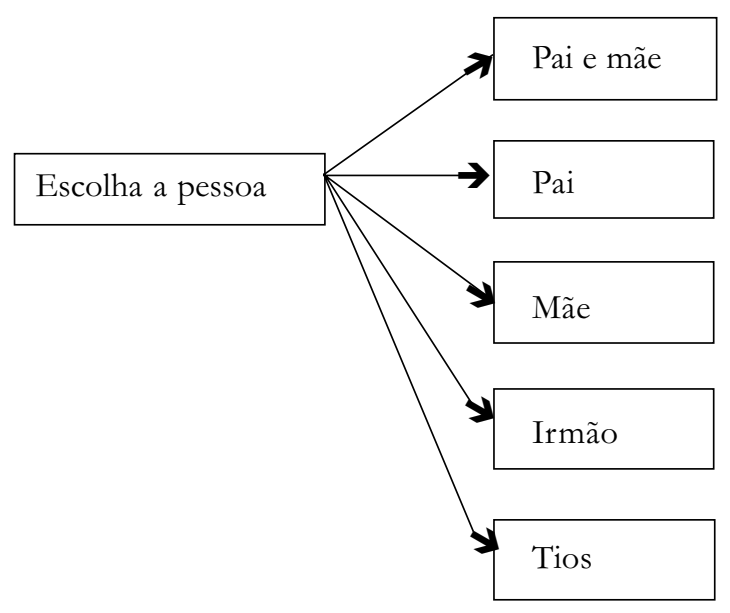

